\title{
Puntos de ruido en San Miguel de Tucumán, investigación, eva- luación y recomendaciones
}

\section{Soundscapes in San Miguel de Tucuman, Argentina: research and trasnfer awarness.}

\begin{abstract}
Beatriz Garzón *
Secretaria de Ciencia, Arte y Innovación Tecnologica. Facultad de Arquitectura y Urbanismo. Universidad Nacional Tecnologica bgarzon@gmail.com

Elisa Soldati ** Secretaria de Ciencia, Arte y Innovación Tecnologica. Facultad de Arquitectura y Urbanismo arquielisa@yahoo.com.ar

Leonardo Paterlini *** Secretaria de Ciencia, Arte y Innovación Tecnologica. Facultad de Arquitectura y Urbanismo paterlinileonardo@gmail.com

Natalia Cerasuolo **** Secretaria de Ciencia, Arte y Innovación Tecnologica. Facultad de Arquitectura y Urbanismo naticerasuolo@gmail.com
\end{abstract}

** María Elisa Soldati, Arquitecta. Especialista en Investigación Educativa, FAU, UNT. Auxiliar docente graduado con semi dedicación, en la Asignatura Acondicionamiento Ambiental II.

*** Leonardo Paterlini, Arquitecto. Becario Conicet "Beca Doctoral Tipo 1". Doctorando en el posgrado de Arquitectura de la Facultad de Arquitectura Planeamiento y Diseño de la Universidad Nacional de Rosario. Seminarista en la Cátedra de Taller Arquitectónico Interdisciplinario, FAU, UNT. Seminarista en la Cátedra de Acondicionamiento Ambiental II, FAU, UNT. Colaborador en la materia "Electiva Sonido y Hábitat", FAU, UNT. Músico

**** Natalia Cerasuolo. Estudiante de séptimo año de la Facultad de Arquitectura y Urbanismo, FAU, UNT. Becaria CIN (Consejo Interuniversitario Nacional). Colaboradora en la materia "Electiva Sonido y Hábitat". 


\section{Resumen}

Este trabajo tiene como propósito la adecuación acústica del microcentro de San Miguel de Tucumán, ya que en él se vive en un constante estado de ruido. Los objetivos de este trabajo son identificar y analizar la contaminación acústica y realizar recomendaciones a la comunidad y al Municipio e Instituciones pertinentes; implementando una estrategia metodológica de Investigación-Acción Participativa. Los resultados alcanzados son: el estudio de diversos puntos de ruido; la evaluación del modo en qué esto afecta a las personas; la elaboración de una serie de recomendaciones para usuarios, Municipios e Instituciones; la generación de material para la concienciación sobre la problemática; la difusión y transferencia de resultados. Se concluye que el microcentro de Tucumán se encuentra bajo una clara polución acústica, generando daños y afecciones en la población. La falta de conocimiento y poca difusión del tema en la sociedad hace urgente la necesidad de crear conciencia al respecto.

Palabras clave: Hábitat Sustentable; Acústica Urbana; Paisaje Sonoro

\section{Abstract}

This paper aims acoustic adequacy of downtown San Miguel de Tucuman, because in it people lives in a constant state of noise. The objectives of this study were to identify and analyze noise and make recommendations to the community and the municipality and institutions; implementing a methodological strategy of Participatory Action Research. The results achieved are: the study of noise points; assessing how this affects people; developing a series of recommendation stousers, municipalities and institutions; material for generating awareness of the problem; dissemination and transfer of results. It is concluded that the down town of Tucuman is under a clear noise pollution damage and creating bad conditions for the population. The lack of knowledge and awareness in society makes urgent the need to create awareness.

Keywords: Sustainable Habitat; Urban acoustics; Sound scape 


\section{Introducción}

El paisaje sonoro se define como un ambiente acústico o un ambiente creado por el sonido. Este puede referirse a entornos naturales o urbanos reales. Cuando el exceso de sonido altera las condiciones normales del ambiente en una determinada zona, genera contaminación acústica, produciendo efectos negativos sobre la salud auditiva, física y mental de los seres vivos. Se llama contaminación acústica o contaminación sonora al exceso de sonido que altera las condiciones normales del ambiente en una determinada zona.

La contaminación por ruido es un problema mundial característico de las sociedades industriales modernas. Debido al aumento poblacional así como al desarrollo del uso de maquinaria y tecnologías que han llevado a nuestra sociedad al nivel de progreso y modernismo del cual disfrutamos hoy, paralelamente éste contaminante invisible se ha instalado y se incrementa en forma permanente, por lo que las generaciones futuras podrían experimentar la degradación de su ambiente social y su calidad de vida.

Actualmente la contaminación sonora se ha convertido en un problema para la salud. Es por ello, que la industria ha aumentado sus esfuerzos para disminuir la emisión de ruido en fuentes específicas. Una opción para facilitar esta determinación de ruido en dichas fuentes,

Figura 1. Escala de valores acústicos en decibeles

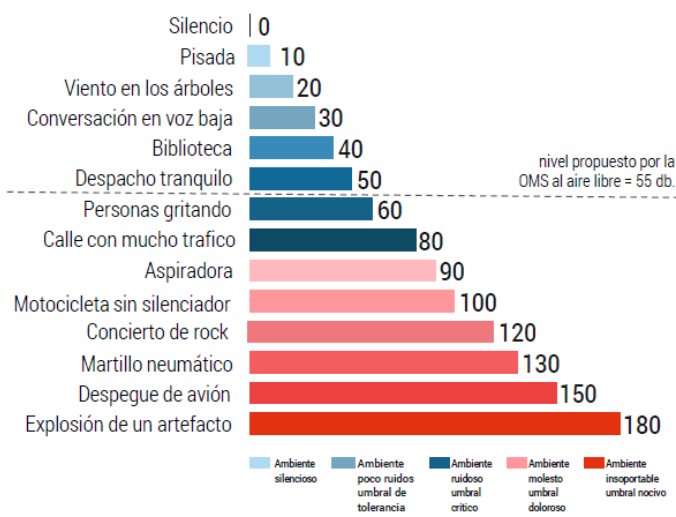

Fuente: Grafico elaborado por el autor. es localizando el punto de dicha fuente donde se genera mayor cantidad de energía sonora.

Los especialistas afirman que la cantidad de ruido en la ciudad ha aumentado en los últimos años y que las consecuencias no sólo se reflejan en el oído, sino fundamentalmente en el cambio de conducta de las personas. Se puede decir que hay dos situaciones que generan un ambiente ruidoso: una es inevitable, generada por las fábricas, las máquinas de construcción o el transporte; y la otra es intencional, producida por los escapes libres de los autos y motos, los bocinazos y la música a alto volumen. El problema actual es que la mayoría del ruido excesivo que se escucha en las calles es intencional.

Las Fuentes que emiten ruidos pueden clasificarse como fuentes de exteriores y de interiores, clasificándose según sea el agente que las causa y la forma en que se transmite. Las fuentes principales de ruido urbano son tránsito automotor, ferroviario y aéreo, la construcción y obras públicas y el vecindario. La organización mundial de la salud (OMS) afirma que el 76\% de la población que vive en los grandes centros urbanos, sufre de un impacto acústico muy superior al recomendable, y esto se refleja en su calidad de vida.

Esta problemática se ve inserta en la provincia de Tucumán, el crecimiento acelerado y

Figura 2. Porcentajes de emisión de ruido

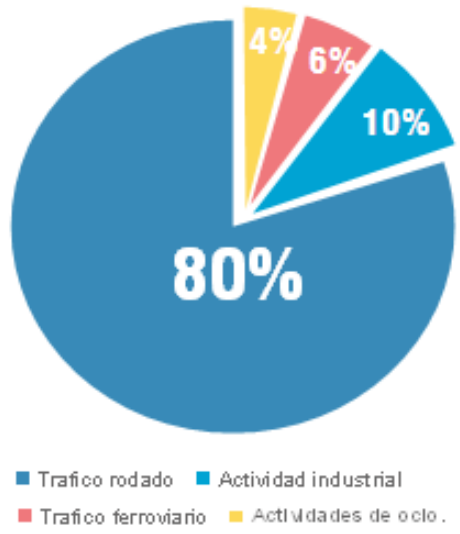

Fuente: Grafico elaborado por el autor según datos establecidos por la ONS. 
el fenómeno de urbanización que se ha producido en la población en los últimos años ha fomentado la contaminación acústica en los distintos paisajes que lo conforman.

La Provincia de Tucumán se encuentra en la región NOA de la República Argentina, punto estratégico geográfico de conexión del norte con el centro del país. Su economía está muy ligada a la producción industrial.

Cuenta con la Universidad Nacional de Tucumán, que es la universidad pública más importante de la región. La misma, funciona como polo de atracción a estudiantes e investigadores, etc. Estos factores, y otros, hacen que Tucumán se sitúe como ciudad cabecera de Región. La población según los datos del Censo 2010 es casi de 1.500 .000 habitantes, siendo un $77 \%$ población urbana. La misma es generadora en gran medida de polución de diferentes índoles, convirtiéndose en productora de gran parte de la contaminación ambiental urbana.

El centro de San Miguel de Tucumán es caóti$c o$, ya que en el mismo se concentran las instituciones en torno a la "Plaza Independencia" (plaza central) y todo el comercio bancario a lo largo de la calle San Martín (que corre de Este a Oeste). Las calles de ronda (fundacionales)

Figura 3. Mapa de Tucumán. Mapa de San Miguel Tucumán.

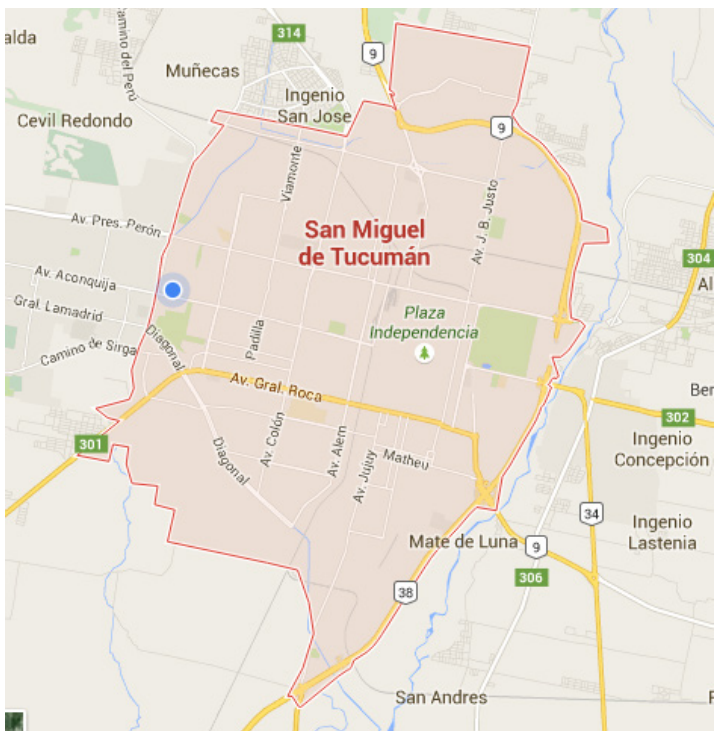

Fuente: Imágenes obtenida de Google Maps.
General Paz, Sáenz Peña, Santiago y Avenida Salta, toman gran volumen del tránsito vehicular que sale desde el microcentro (casco fundacional).

El factor del tránsito y su constante crecimiento, falta de una regulación al respecto y poca inversión privada y estatal en el servicio público de transporte de pasajeros hace de éste el factor principal de producción de contaminación acústica en la ciudad.

El problema del ruido en San Miguel de Tucumán es conocido, ha sido tratado y denunciado numerosas veces en publicaciones en los diarios de tirada provincial más importantes. "El ruido ocupa un lugar en el espacio sonoro de la ciudad. Basta permanecer un rato en las horas pico en la calle Santiago del Estero, entre Laprida y 25 de Mayo, o en Crisóstomo Álvarez, entre Chacabuco y Entre Ríos, para comprobar la polución sonora, que padecemos como si fuera natural" (La Gaceta, 2015). Existen en la actualidad normativas vigentes en la provincia, pero no son aplicadas como deberían o ni siquiera son de público conocimiento.

\section{Objetivo General:}

Considerando los antecedentes sobre el alto grado de contaminación sonora que presenta la ciudad y la necesidad de resolver esta problemática, se busca identificar y analizar puntos de ruido en San Miguel de Tucumán, para detectar el nivel de contaminación acústica, e informar y realizar recomendaciones a la comunidad y al municipio e instituciones pertinentes, para establecer medidas de concienciación y compromiso en la población.

\section{Objetivos Específicos:}

Identificar cuáles son los puntos urbanos de la ciudad de San Miguel de Tucumán que tienen problemas de ruido, teniendo en cuenta aquellos puntos de la ciudad conocidos por la experiencia de usuario que son polos de polución acústica. 
Figura 4. Tránsito vehicular en el centro de San Miguel de Tucumán

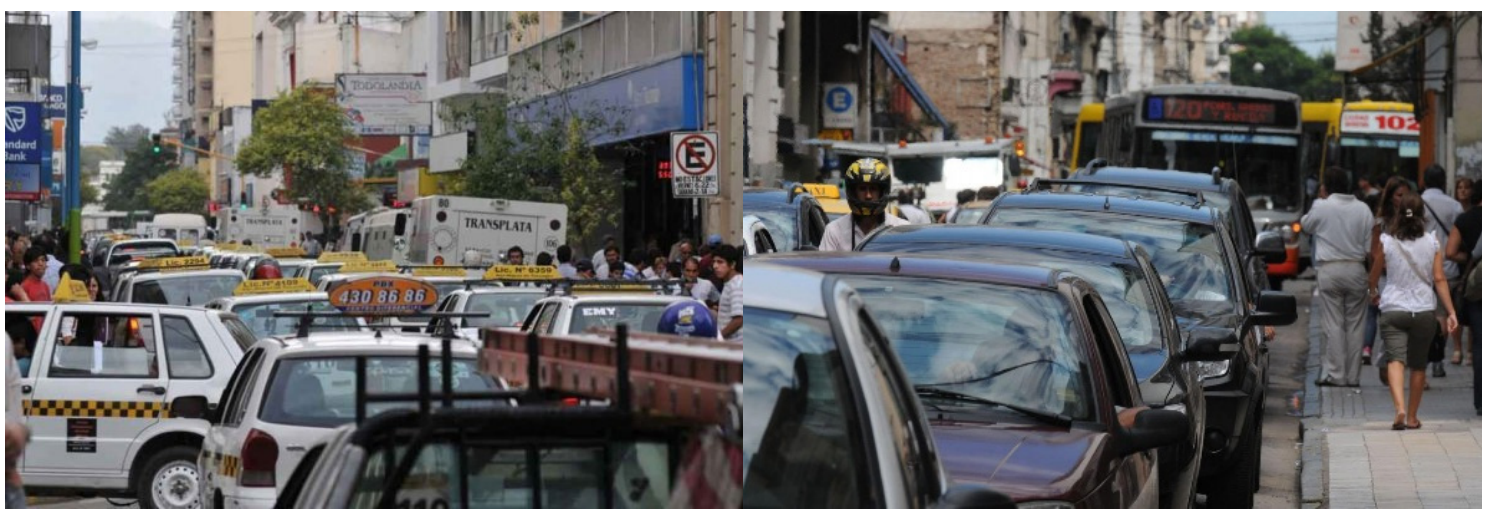

Fuente: Imágenes obtenidas del periódico "LA GACETA".

Investigar dichos lugares y clasificarlos según el conocimiento en la temática existente; determinar cuáles son aquellos ruidos que están produciendo la polución acústica y realizar una clasificación de las áreas en estudio, según tipos de ruidos y rangos de intensidad a la que están siendo sometidas.

Relevar dichos sectores con instrumental apropiado acústico (sonómetro).

Analizar los resultados obtenidos en los diferentes sectores de muestreo, en los paisajes seleccionados.

Analizar y generar diferentes métodos para la transferencia de los mismos, implementando medidas de control y concientización en las poblaciones que habitan estos paisajes.

\section{Metodología}

A partir de este acercamiento a la situación de la ciudad, se realizan diferentes lecturas, además de la propia experiencia como usuarios, se establecen focos de contaminación acústica y se los clasifica según su potencial producción de ruido, teniendo en cuenta su ubicación, cantidad de tránsito, y otros factores que pudieran producir ruido en tales puntos.

\section{A) Sectores seleccionados para su análisis:}

1. Calle 25 de Mayo entre Córdoba y Mendoza (calle 25 de Mayo corre en sentido Norte a Sur, es la más importante en lo que respecta a la actividad comercial)

2. Esq. Calles Salta y San Martín (calle Salta, corre de Norte a Sur, es una de la arterias que toma gran volumen de tránsito vehicular en horario comercial).

3. Esq. Calles Córdoba y Rivadavia (calle Córdoba lleva gran parte del tránsito de transporte público además de ser una arteria conectora de la ciudad en sentido Este a Oeste)

4. Esq. Calles Crisóstomo Alvares y Jujuy (calle Crisóstomo \{Alvarez corre en sentido Oeste a Este, y se caracteriza por el gran número de colectivos que transitan por ella).

5. Esq. Calles General Paz y Chacabuco (calle General Paz corre en sentido Oeste a Este, y toma gran volumen del tránsito vehicular).

6. Esq. Calles Chacabuco y Las Piedras (se caracteriza por la concentración de bares, drugstores, y kioscos que generan gran circulación peatonal como vehicular.)

\section{B) Protocolo de medición}

Al tratarse de una medición con cierto grado de subjetividad se decide realizar previamente a los ensayos un protocolo de medición que será el que le dé cierto marco de especificad y rigurosidad a las mediciones. Las mismas serán realizadas en ámbitos urbanos, haciendo un 
relevamiento con sonómetro, además de fotográfico y de video.

Las pautas decididas a tomar son:

1. Las mediciones serán siempre hechas por la misma persona, utilizando un sonómetro que no guarda en su memoria las diferentes mediciones. Otro sujeto será quien vaya tomando nota de las distintas mediciones y de los eventos que producen los picos de decibelios en el aparato.

2. Todas las mediciones se realizarán el mismo día. El mismo deberá ser un día de normal uso de la ciudad (día hábil) entre las 9 y las 13 horas.

3. Las mediciones se realizarán en mano del operador, respetando una altura de 1.60 metros respecto del nivel de vereda, y a una distancia de 2 metros de la calle. En los casos de esquina, será en diagonal a la misma.

4. Cada medición tendrá una duración de 10 minutos.

5. La lectura del medidor sonoro se realizaran en compensación A en respuesta S (lenta) para mediciones promedio en un intervalo de tiempo de 2 minutos, y en respuesta MAX HOULD para mediciones de ruidos muy altos en un intervalo de tiempo de 5 minutos.

Figura 6. Sonómetro. Protocolo de Medición
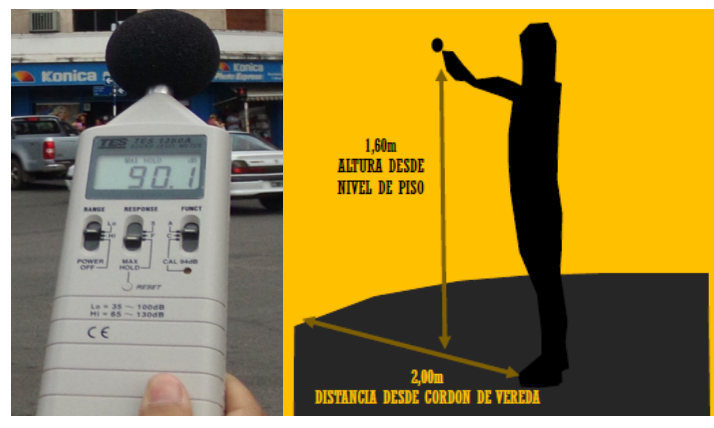

Fuente: Imágenes elaboradas por el autor

\section{Resultados}

Las mediciones se realizaron en la ciudad de San Miguel de Tucumán entre los meses de abril y septiembre de 2015.

Las siguientes mediciones corresponden a los 6 sectores elegidos, por ser los más relevantes en intensidad y frecuencia de ruidos:

Figura 5. Mapa San Miguel de Tucumán, Zona Céntrica, con sectores a analizar

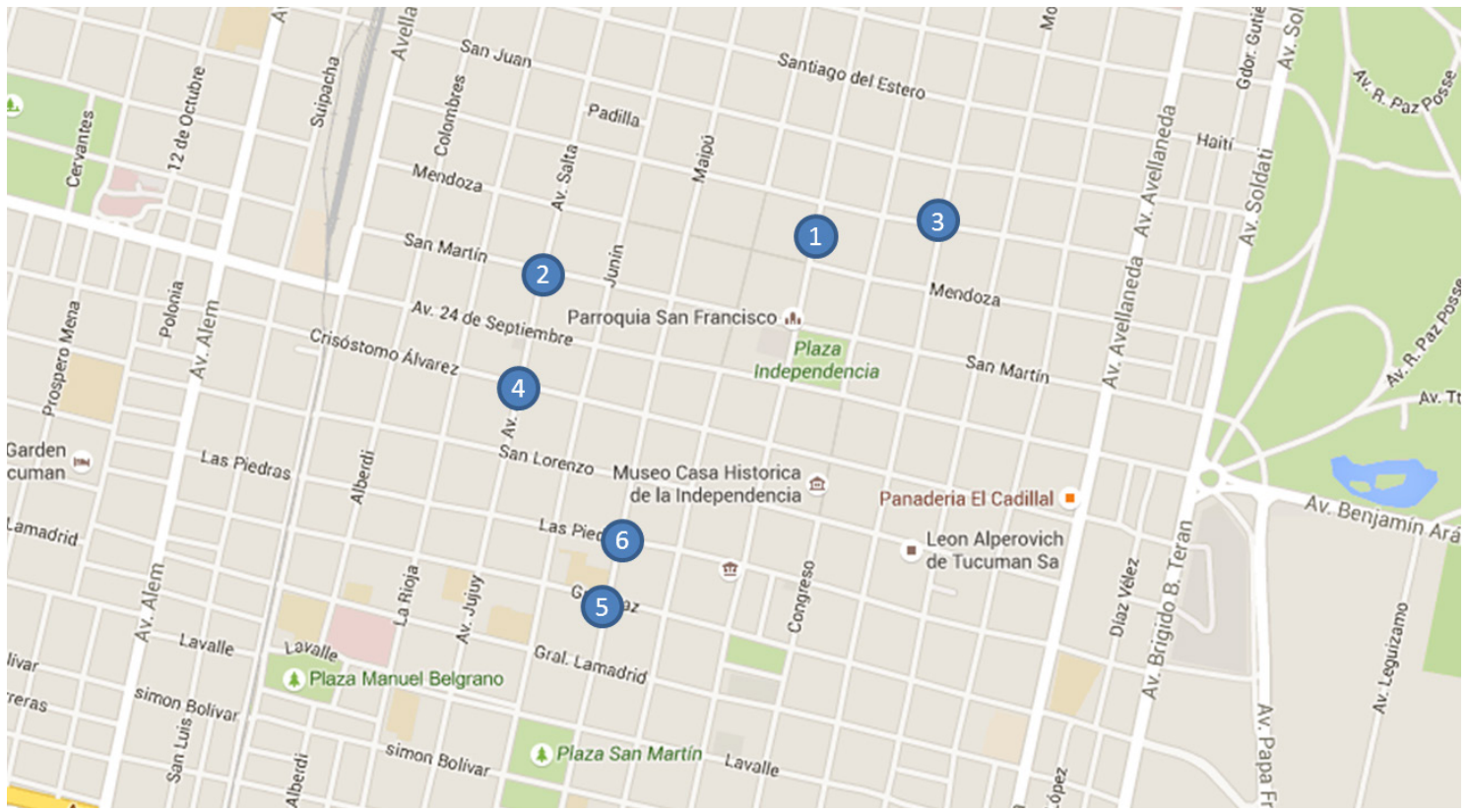

Fuente: Imágenes elaboradas por el autor 
Tabla 1. Calle 25 de Mayo entre Córdoba y Mendoza

\begin{tabular}{|c|c|c|c|c|c|c|c|}
\hline \multirow{4}{*}{ Fecha } & \multicolumn{2}{|c|}{ Horario } & \multicolumn{2}{|c|}{ Transito } & Peatones & \multicolumn{2}{|c|}{ Respuestas } \\
\hline & \multirow{3}{*}{ Inicio } & \multirow{3}{*}{ Fin. } & Vehicular & Trasporte Publico & Flujo Peatonal & \multirow{3}{*}{ Respuesta Slow } & \multirow{3}{*}{ Respuesta Max Hold } \\
\hline & & & \multirow{2}{*}{ alta/medio/baja } & Frecuencia & \multirow{2}{*}{ alto/media/ajajo } & & \\
\hline & & & & alta/media/ıаja & & & \\
\hline $06 / 04 / 2015$ & $10: 35$ & $10: 45$ & al to & alta & alta & $69,9 d B$ & $86,9 d B$ \\
\hline
\end{tabular}

Fuente: Tabla realizada por el autor.

Figura 7. Sector Calle 25 de Mayo entre Córdoba y Mendoza. Medición de los ruidos en la misma.

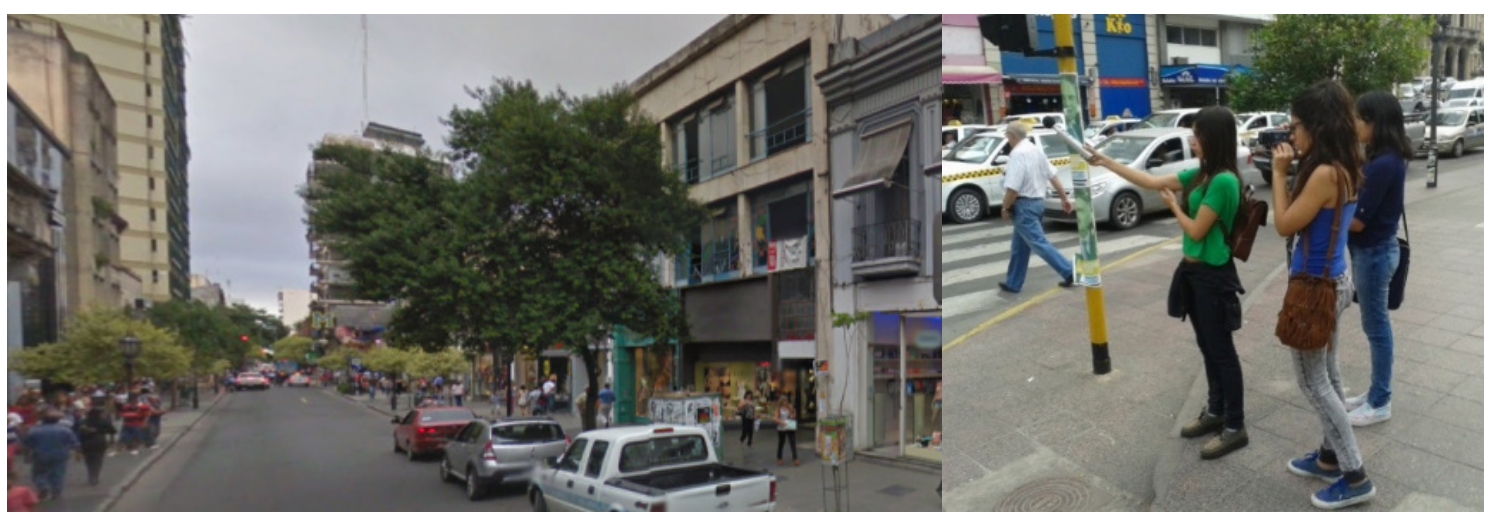

Fuente: Imágenes capturadas por el autor.

Tabla 2. Calles Salta y San Martin

\begin{tabular}{|c|c|c|c|c|c|c|c|}
\hline \multicolumn{8}{|c|}{ Planilla de Medición 2: Esq. Calles Salta y San Martín } \\
\hline \multirow{4}{*}{ Fecha } & \multicolumn{2}{|c|}{ Horario } & \multicolumn{2}{|c|}{ Transito } & Peatones & \multicolumn{2}{|c|}{ Respuestas } \\
\hline & \multirow{3}{*}{ Inicio } & \multirow{3}{*}{ Fin. } & Vehicular & Trasporte Publico & Flujo Peatonal & \multirow{3}{*}{ Respuesta Slow } & \multirow{3}{*}{ Respuesta Max Hold } \\
\hline & & & \multirow{2}{*}{ al ta/med ia/tbaja } & Frecuencia & \multirow{2}{*}{ alta/media/tajo } & & \\
\hline & & & & alta/media/מaja & & & \\
\hline $06 / 04 / 2015$ & $11: 18$ & $11: 28$ & al to & alta & alta & $79,2 d B$ & $90,7 d B$ \\
\hline
\end{tabular}

Fuente: Tabla realizada por el autor.

Tabla 3. Calles Córdoba y Rivadavia

\begin{tabular}{|c|c|c|c|c|c|c|c|}
\hline \multirow{4}{*}{ Fecha } & \multicolumn{2}{|c|}{ Horario } & \multicolumn{2}{|c|}{ Transito } & \multirow{2}{*}{\begin{tabular}{|c|} 
Peatones \\
Flujo Peatonal \\
\end{tabular}} & \multicolumn{2}{|c|}{ Respuestas } \\
\hline & \multirow{3}{*}{ Inicio } & \multirow{3}{*}{ Fin. } & Vehicular & Trasporte Publico & & \multirow{3}{*}{ Respuesta Slow } & \multirow{3}{*}{ Respuesta Max Hold } \\
\hline & & & \multirow{2}{*}{ al to/med ia/toja } & Frecuencia & \multirow{2}{*}{ alt $a /$ media/tojjo } & & \\
\hline & & & & alta/media/tıja & & & \\
\hline $06 / 04 / 2015$ & $9: 40$ & $9: 50$ & medio & medio & medio & $66,4 d B$ & $87,6 d B$ \\
\hline
\end{tabular}

Fuente: Tabla realizada por el autor.

Tabla 4. Calles Crisóstomo Alvares y Jujuy

\begin{tabular}{|c|c|c|c|c|c|c|c|}
\hline & & & Inilla de & lición 4: Esq. Cal & Crisóstomo A & vares y Jujuy & \\
\hline \multirow{4}{*}{ Fecha } & \multicolumn{2}{|c|}{ Horario } & \multicolumn{2}{|c|}{ Transito } & Peatones & \multicolumn{2}{|c|}{ Respuestas } \\
\hline & \multirow{3}{*}{ Inicio } & \multirow{3}{*}{ Fin. } & Vehicular & Trasporte Publico & Flujo Peatonal & \multirow{3}{*}{ Respuesta Slow } & \multirow{3}{*}{ Respuesta Max Hold } \\
\hline & & & \multirow{2}{*}{ alto/media/baja } & Frecuencia & \multirow{2}{*}{ alta/medio/bajo } & & \\
\hline & & & & alta/media/baja & & & \\
\hline $28 / 09 / 2015$ & 19:31 & $19: 41$ & medio & medio & medio & $74,1 d B$ & $89,5 d B$ \\
\hline
\end{tabular}

Fuente: Tabla realizada por el autor.

æ Área Editorial Fau | 
Tabla 5. Calles General Paz y Chacabuco

\begin{tabular}{|c|c|c|c|c|c|c|c|}
\hline \multirow{4}{*}{ Fecha } & Horario & ario & \multicolumn{2}{|c|}{ Transito } & Peatones & \multicolumn{2}{|c|}{ Respuestas } \\
\hline & \multirow{3}{*}{ Inicio } & \multirow{3}{*}{ Fin. } & Vehicular & Trasporte Publico & Flujo Peatonal & \multirow{3}{*}{ Respuesta Slow } & \multirow{3}{*}{ Respuesta Max Hold } \\
\hline & & & \multirow{2}{*}{ al ta/medio/baja } & Frecuencia & \multirow{2}{*}{ alto/medio/ıjajo } & & \\
\hline & & & & alta/media/taja & & & \\
\hline $28 / 09 / 2015$ & $18: 23$ & $18: 33$ & alto & medio & alto & $88,6 d B$ & $91,5 d B$ \\
\hline
\end{tabular}

Fuente: Tabla realizada por el autor.

Tabla 6. Calles Chacabuco y Las Piedras

\begin{tabular}{|c|c|c|c|c|c|c|c|}
\hline \multirow{4}{*}{ Fecha } & \multicolumn{2}{|c|}{ Horario } & \multicolumn{2}{|c|}{ Transito } & \multirow{2}{*}{\begin{tabular}{|c|} 
Peatones \\
Flujo Peatonal
\end{tabular}} & \multicolumn{2}{|c|}{ Respuestas } \\
\hline & \multirow{3}{*}{ Ini cio } & \multirow{3}{*}{ Fin. } & Vehicular & Trasporte Publico & & \multirow{3}{*}{ Respuesta Slow } & \multirow{3}{*}{ Respuesta Max Hold } \\
\hline & & & \multirow{2}{*}{ alto/med ia/baja } & Frecuencia & \multirow{2}{*}{ alto/medio/bajo } & & \\
\hline & & & & alta/media/taja & & & \\
\hline $28 / 09 / 2015$ & 19:03 & $19: 13$ & al to & bajo & alta & $76,5 d B$ & $88,3 d B$ \\
\hline
\end{tabular}

Fuente: Tabla realizada por el autor.

Figura 8. Calles Chacabuco y Las Piedras

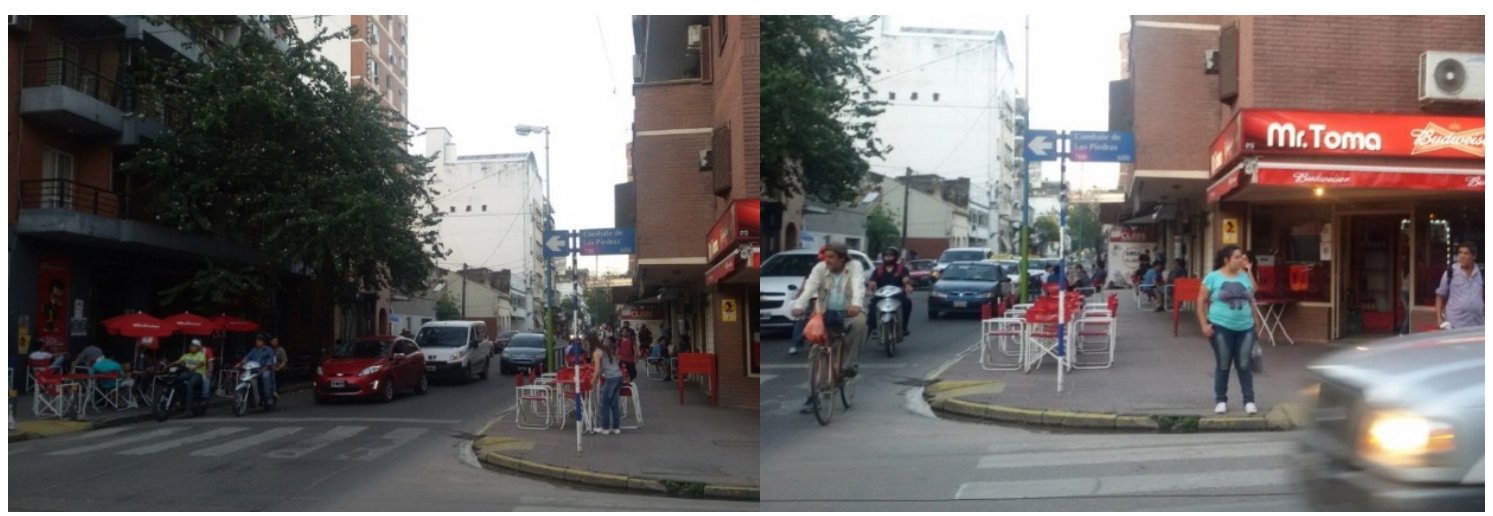

Fuente: Imágenes capturadas por el autor.

\section{Causas}

Se puede apreciar que gran parte del sonido producido en los distintos puntos estudiados pueden ser generado por diferentes fuentes sonoras, como ser: bullicio, bocinazos, escapes de motos, sirenas de ambulancia, sirenas de policía, alarmas de emergencia, frenadas de colectivos, etc. Sin embargo la contaminación sonora tiene como protagonista principal a las vías de circulación rápida, éstas debido a su aspecto físico (angostas y con problemas de mantenimiento debido al gran tránsito al que están sometidas) y disposición de masas (edificios) reflejan el ruido generando así espacios totalmente descontrolados acústicamente, con embotellamientos y concentración vehicular en horas pico, volviéndose a su vez intransitables para el peatón.

\section{Consecuencias}

A partir de los resultados alcanzados con las mediciones de cada sector, podemos decir que la ciudad está sometida durante los días de normal funcionamiento a niveles sonoros que son perjudiciales para la salud de las personas. Los ruidos urbanos generados son casi en su totalidad por el tránsito de vehículos, privados, públicos o de transporte público. Como se mencionó anteriormente existen normativas y reglamentaciones en la ciudad, pero no son aplicadas en tales casos como los del tránsito.

\section{Repercusiones en la Salud}

Los especialistas provinciales afirman que la cantidad de ruido en la ciudad ha aumentado en 
los últimos años y que las consecuencias no sólo se reflejan en el oído, sino fundamentalmente en el cambio de conducta de las personas.

Las mediciones acústicas indican que, en horario pico, el centro de San Miguel de Tucumán soporta sonidos de entre 90 y 100 dB, cuando los valores establecidos por la OMS (Organización mundial de la Salud) establecen que el valor óptimo para un nivel de confort acústico es de $55 \mathrm{~dB}$, teniendo en cuenta que después de los 65 dB el ruido es dañino, lo que nos indica que la metrópolis es muy agresiva para el oído humano.

\section{Propuestas}

\section{A) Soluciones}

La contaminación acústica es un problema que podemos mejorar entre todos (instituciones, administraciones y sociedad) contribuyendo a reducir los niveles de ruido aplicando las normas y ordenanzas vigentes, y creando otras complementarias que se hagan cumplir.

Para poder lograr disminuir los niveles de contaminación, es imprescindible generar una buena concientización de la sociedad sobre los problemas que el ruido puede causar, generando recomendaciones tanto para los individuos como para el municipio.

B) Recomendaciones

- Para individuos: ayudar a la comunidad a estar en silencio.

- No tocar la bocina innecesariamente, solo cuando sea absolutamente necesario: para informarle a alguien que estás presente o para advertirle si está a punto de chocar con algo.

- Mantener el auto bien reparado, con silenciador para evitar ruidos molestos en las vías de circulación.

- Respetar las horas de silencio por la noche.

- Para el Municipio: brindar una mejor calidad de vida a la sociedad disminuyendo la contaminación acústica.

- Proteger a la población del ruido urbano y considerarlo como parte integral de su

- Política de protección ambiental, mediante el cumplimiento de las normativas vigentes.

- Implementar planes de acción con objetivos

Figura 9: Tabla con efectos en la salud

\begin{tabular}{|c|c|c|c|}
\hline Desiveles & Entre 70 y 80 & Entre 80 y 90 & Mayores a 90 \\
\hline Efectos & Otros efectos & Pérdida temporal de audición & Pérdida permanente de audición \\
\hline $\begin{array}{l}\text { Problemas } \\
\text { en la salud }\end{array}$ & $\begin{array}{l}\text { Problemas de salud crónicos: La } \\
\text { ex posición al ruido durante } \\
\text { mucho tiempo disminuye la } \\
\text { coordinación y la concentración, } \\
\text { el ruido aumenta la tensión, } \\
\text { genera trastornos cardíacos, } \\
\text { estomacales y nerviosos. El ruido } \\
\text { es una de las causas de las } \\
\text { enfermedades cardíacas y las } \\
\text { úlceras de estómago. También } \\
\text { puede causar nerviosismo, } \\
\text { insomnio y fatiga. }\end{array}$ & $\begin{array}{l}\text { Al cabo de breve tiempo en un } \\
\text { lugar de trabajo ruidoso a veces } \\
\text { se nota que no se puede oír muy } \\
\text { bien y quelezumban a uno los } \\
\text { oidos. El zumbido y la sensación } \\
\text { de sordera desaparec en } \\
\text { normalmenteal cabo de poco } \\
\text { tiempo de estar alejado del ruido. } \\
\text { Ahora bi en, cuanto más tiempo se } \\
\text { esté expuesto al ruido, más tiempo } \\
\text { tarda el sentido del oído en volver } \\
\text { a ser "normal". }\end{array}$ & $\begin{array}{l}\text { Con el paso del tiempo, des pués de } \\
\text { haber estado expuesto a un ruido } \\
\text { excesivo durante demasiado } \\
\text { ti empo, los oídos no se recuperan } \\
\text { y la pér di da de audición pasa a } \\
\text { ser permanente. La pérdida } \\
\text { permanente de audición no ti ene } \\
\text { cura. Este tipo de lesión del } \\
\text { sentido del oído puede deberse a } \\
\text { una exposición prolongada a } \\
\text { ruido el evado o, en algunos casos, } \\
\text { a exposiciones breves a ruidos } \\
\text { elevadísimos. }\end{array}$ \\
\hline
\end{tabular}

Fuente: Grafico elaborado por el autor. 
de corto, mediano y largo plazo para reducir los niveles de ruido. Por ejemplo: el reordenamiento del tránsito para una circulación vehicular más fluida, el ensanchamiento de calles y la incorporación de mayor arbolado en espacios públicos.

- Adoptar las "Guías de salud" para generar conciencia en la población disminuyendo el ruido urbano como metas de largo plazo.

- Generar medios y herramientas de concientización para la sociedad (folletos, cartillas, videos, talleres, charlas, etc.)

- Incluir el ruido como un tema de salud pública importante en la evaluación del impacto ambiental.

- Adecuar la legislación vigente para reducir los niveles de ruido.

- Aplicar la normativa existente. Ejemplo, Normas Iram número 4044 1998; Ordenanza 288/78: Ruidos molestos; Ordenanza 254797 : Ruidos y sonidos innecesarios.

Los municipios deben elaborar planes de reducción de ruidos.

- Evaluar la efectividad de los cambios propuestos a corto y largo plazo en función de los costos. Los análisis de costo-beneficio se deben considerar como instrumentos potenciales de las decisiones gerenciales importantes.

- Apoyar proyectos de investigación dirigidos a la búsqueda de problemas sonoros en las distintas áreas del Gran San Miguel de Tucumán, con el fin de detectar el nivel de contaminación acústica e informar y realizar recomendaciones a la comunidad y a los municipios e instituciones pertinentes.

- Generar líneas de investigación con posibles soluciones en los centros urbanos.

\section{Conclusión}

1. A diferencia de otros problemas ambientales, la contaminación acústica sigue en aumento y produce un número cada vez mayor de reclamos por parte de la población. Ese incremento no es sostenible debido a las consecuencias adversas, tanto directas como acumulativas, que tiene sobre la salud, que afectara a las generaciones futuras con repercusiones socioculturales, estéticas y económicas.

2. Las mediciones acústicas indican que, en horario pico, el centro de San Miguel de Tucumán soporta sonidos de entre 90 y 100 dB, teniendo en cuenta que después de los $65 \mathrm{~dB}$ el ruido es dañino, la metrópolis es muy agresiva para el oído humano. Ruido de bocinas, motores, música y gritos configuran el entorno de quien recorre las calles de la ciudad. Parece que en la sociedad actual hacer ruido es un derecho, y soportarlo una obligación.

3. Existe un alto desconocimiento de la población al respecto de los problemas que puede traer aparejado el exceso de ruido en la vida cotidiana. Por esta razón es necesario, como primera medida que cada individuo tome consciencia de producir un cambio en sus hábitos de comportamiento, los cuales generan en menor o mayor medida contaminación acústica en su medio ambiente. Como segunda medida es necesario que las leyes que se encuentran en vigencia se las hagan cumplir y se las respete, y para los casos en los que no se posea una ley específica, se deberá crearla y hacerla cumplir para el bienestar colectivo de toda la sociedad. 


\section{Bibliografía}

10 cosas que deberías saber sobre la contaminación acústica. Disponible en: http://www.fundacionmelior. org/content/tema/10-cosas-que-deberias-saber-sobre-la-contaminacion-acustica (acceso 22/10/2015) Archivo "La Gaceta" - "La contaminación Sonora pone agresiva a las personas" - Tucumán, Argentina - 14 de febrero de 2007

Declaración de la AMM sobre la Contaminación Acústica. Disponible en: http://www.wma.net/ es/30publications/10policies/n3/ (acceso 24/10/2015)

Efectos de la contaminación acústica en la salud. Disponible en: http://ecodes.org/noticias/efectos-de-lacontaminacion-acustica-sobre-la-salud\#.VjKJq9lvdkg (acceso 19/10/2015)

Municipalidad de San Miguel de Tucumán. La ciudad. Información básica. Disponible en:

http://www.sanmigueldetucuman.gov.ar/ciudad_1.php (acceso 19/10/2015)

Plan estratégico urbano Territorial para la Ciudad de San Miguel de Tucumán SMT2016 - Municipalidad de San Miguel de Tucumán, 2010.

Paisajes Sonoros en San Miguel de Tucumán, Argentina: Investigación y Transferencia para su conciencia-ción. Garzón, B., Soldati, E., Paterlini, L., Perera, S., Rufino, M., Orellana, M., Ponce, F. 46 Congreso Español de Acústica. Tecn 